\title{
QUALIDADE FISIOLÓGICA DE SEMENTES DE FEIJÃO EM FUNÇÃO DA POPULAÇÃO DE PLANTAS E NITROGÊNIO EM PLANTIO DIRETO
}

\author{
COSTA, Roberto Savério Souza ${ }^{106}$ \\ SÁ, Marcos Eustáquio de ${ }^{107}$ \\ ORIOLI JÚNIOR, Valdeci ${ }^{108}$ \\ BERTOLIN, Danila Comelis ${ }^{109}$
}

Recebido em: 2008-07-24

Aprovado em: 2008-08-2

ISSUE DOI: $10.3738 / 1982.2278 .121$

RESUMO: O primeiro fator a ser observado no estabelecimento de uma lavoura é a qualidade das sementes, fator que pode ser influenciado pela adubação nitrogenada. Assim, com o objetivo de avaliar a qualidade fisiológica de sementes de feijão em função de três populações de plantas e da adubação nitrogenada na semeadura e em cobertura, conduziu-se um experimento em um Latossolo Vermelho distrófico em delineamento de blocos casualizados em esquema fatorial 3x2x5, sendo, três populações de plantas (200, 240 e 300 mil plantas por ha), duas doses de $\mathrm{N}$ em semeadura (10 e $20 \mathrm{~kg} / \mathrm{ha}$ ) e cinco doses de $\mathrm{N}$ em cobertura $(0,25,50,75$ e 100 $\mathrm{kg} / \mathrm{ha}$ ). Foram realizadas as seguintes avaliações: teste padrão de germinação, primeira contagem, índice de velocidade de germinação, envelhecimento acelerado e condutividade elétrica. Concluiu-se que menores populações de plantas proporcionam melhor qualidade fisiológica das sementes, pois apresentam sementes com maior vigor, evidenciado através do teste de envelhecimento acelerado. As diferentes doses de nitrogênio tanto na semeadura quanto em cobertura, não interferem na qualidade fisiológica do feijoeiro.

Palavras-chave: Phaseolus vulgaris. Adubação nitrogenada. Espaçamento entrelinha. Vigor.

\section{PHYSIOLOGIC QUALITY OF BEAN SEEDS IN FUNCTION OF THE PLANTS POPULATION AND NITROGEN IN NO TILL}

SUMMARY: The first factor to be observed in the establishment of a farming is the seeds quality, factor that can be influenced by the nitrogen fertilization. Thus, with the objective of evaluating the physiologic quality of bean seeds in function of three plants populations and sowing or sidedressing nitrogen fertilization, was carried an experiment in a Typic Acrustox in randomized blocks design with four replications in factorial scheme $3 \times 2 \times 5$, being, three plants populations (200, 240 and 300 thousand plants for hectare), two $\mathrm{N}$ rates in sowing (10 and 20 $\mathrm{kg} /$ there is) and five sidedressing $\mathrm{N}$ rates $(0,25,50,75$ and $100 \mathrm{~kg} /$ there is). The following evaluations were accomplished: standard germination test, first counting, germination speed index, accelerated aging and electric conductivity. Smaller plants populations provide better physiologic quality of the seeds, because they present

\footnotetext{
${ }^{106}$ Mestre em Agronomia - Bunge Fertilizantes S.A.

${ }^{107}$ Prof. Dr. do Departamento de Fitotecnia, Tecnologia de Alimentos e Sócio-Economia. UNESP - Campus de Ilha Solteira.

${ }^{108}$ Mestrando em Agronomia (Produção Vegetal). UNESP - Campus de Jaboticabal. Bolsista CAPES. E-mail: orioli.jr@hotmail.com

${ }^{109}$ Doutoranda em Agronomia (Sistemas de Produção). UNESP - Campus de Ilha Solteira.
} 
seeds with larger vigor, evidenced through the accelerated aging test. The sowing or sidedressing application does not interfere in the physiologic quality of the bean.

Key words: Phaseolus vulgaris. Nitrogen fertilization. Row spacing. Vigor.

\section{INTRODUÇÃO}

No Brasil, o feijão comum representa o terceiro produto em área semeada e o quarto em valor de produção agrícola. O esforço da pesquisa em obter melhores níveis de produtividade e garantir o abastecimento interno do produto é justificado pela importância social do feijão como alimento substituto de proteínas e rico em ferro, e pelo consumo generalizado da população brasileira.

O primeiro fator a ser observado no estabelecimento de uma lavoura é a qualidade das sementes, que pode ser expressa pela interação de quatro componentes: genético, físico, sanitário e fisiológico (AMBROSANO et al. 1999). De acordo com Vieira et al. (1993), o componente fisiológico pode ser influenciado pelo ambiente em que as sementes se formam. Deste modo, também a adubação influenciará a qualidade das sementes. Porém, trabalhos que objetivam relacionar adubação e nutrição das plantas com a qualidade fisiológica das sementes são em número reduzido e os resultados nem sempre são concordantes (CARVALHO et al. 2001).

Concernente à adubação, sabe-se que o $\mathrm{N}$ é o nutriente que mais se relaciona com a produção das culturas e para Carvalho; Nakagawa (2000), o N também pode influenciar a qualidade fisiológica das sementes. Contudo, tal influência dependerá das condições ambientais e do estágio de desenvolvimento em que este nutriente é fornecido para as plantas.

No entanto, constata-se grande carência de informações que relacionem a quantidade de $\mathrm{N}$ fornecido e seu parcelamento com aspectos fisiológicos das sementes. Os estudos de adubação nitrogenada em feijoeiro, em sua maioria, abordam o efeito dos fatores supracitados nos componentes de produção.

Ainda, a avaliação da qualidade fisiológica da semente para fins de semeadura em campo e de comercialização de lotes tem sido fundamentalmente baseada no teste de germinação. $\mathrm{Na}$ busca de metodologia com sensibilidade suficiente para avaliar com maior precisão o nível de deterioração das sementes, foram desenvolvidos os testes de vigor, que têm se constituído em excelentes instrumentos auxiliares nos processos de decisão na produção, armazenamento e 
comercialização de sementes. Fica evidente, portanto, a necessidade da execução de mais estudos sobre a adubação/nutrição e a qualidade fisiológica das sementes de feijão, objetivando não só a qualidade, mas, também, a elevação da produtividade (CARVALHO et al. 2001).

Não obstante a grande ênfase que tem sido dada aos testes para avaliar a qualidade fisiológica das sementes é possível constatar a escassez de informações a respeito destes testes com sementes, cultivadas em diferentes populações de plantas. Assim sendo, esta pesquisa teve por objetivo a avaliação da qualidade fisiológica de sementes de feijão em função de três populações de plantas e da adubação nitrogenada na semeadura e em cobertura.

\section{MATERIAL E MÉTODOS}

O trabalho foi conduzido em área experimental pertencente à Faculdade de Engenharia - UNESP, Campus de Ilha Solteira, localizada no município de Selvíria - MS, que foi anteriormente ocupada cultivada com milho para produção de grãos. O solo da área é classificado como Latossolo Vermelho distrófico (EMBRAPA, 1999). Nesse estudo as parcelas foram constituídas de cinco linhas de $7 \mathrm{~m}$ de comprimento, considerando como área útil as três linhas centrais e eliminando-se 0,5 metros das extremidades de cada linha. As análises foram realizadas no Laboratório de Sementes da mesma instituição.

Adotou-se o delineamento experimental de blocos casualizados em esquema fatorial $3 \times 2 \times 5$, sendo três populações de plantas (200; 240 e 300 mil plantas por ha), duas doses de N aplicadas em semeadura (10 e $20 \mathrm{~kg} / \mathrm{ha}$ ) e cinco doses de $\mathrm{N}$ em cobertura (zero, 25, 50, 75 e $100 \mathrm{~kg} / \mathrm{ha}$ ), utilizando-se a uréia como fonte do nutriente.

A semeadura foi realizada, utilizando-se o cultivar Pérola, com sementes necessárias para se obter 12 plantas por metro, variando-se o espaçamento entrelinhas $(0,40 ; 0,50$ e 0,60m) de acordo com a população de plantas por hectare desejada. Para o tratamento de sementes, utilizou-se o fungicida carboxin + thiran $(200+200 \mathrm{~g}$ do ingrediente ativo/100 $\mathrm{kg}$ de sementes). Na adubação básica de semeadura, utilizaram-se $250 \mathrm{~kg} / \mathrm{ha}$ da fórmula 4-30-10 + 0,4\% de zinco. De acordo com os tratamentos, as parcelas que necessitavam de $20 \mathrm{~kg}$ de nitrogênio/ha foram complementadas com adubação nitrogenada na forma de uréia. Após a semeadura, a área foi irrigada por meio de um pivô central com uma lâmina de água de aproximadamente $14 \mathrm{~mm}$ para promover a germinação das sementes.

Seguindo as recomendações de Ambrosano et al. (1996), aos 16 dias após a emergência (fase $V_{3}$ de desenvolvimento) foi realizada a adubação nitrogenada de cobertura 
nas doses $0,25,50,75$ e $100 \mathrm{~kg} /$ há, conforme os tratamentos, também tendo a uréia como fonte.

Após a colheita dos grãos, as amostras foram armazenadas em sacos de papel e efetuou-se as análises referentes à qualidade fisiológica das sementes, descritas a seguir.

A determinação do grau de umidade foi realizada em estufa, a $105^{\circ} \mathrm{C}+-3^{\circ} \mathrm{C}$, durante 24 horas, utilizando-se duas amostras para cada lote, sendo os resultados expressos em porcentagem. Para o teste padrão de germinação, foram utilizadas quatro amostras de 50 sementes por lote, semeadas em rolo de papel toalha tipo Germitest, umedecido com quantidade de água equivalente a 2,5 vezes o peso do substrato e colocadas para germinar à $25^{\circ} \mathrm{C}$. As avaliações foram realizadas aos cinco e nove dias após a semeadura (BRASIL, 1992). A primeira contagem de germinação foi conduzida conjuntamente com o teste padrão de germinação, consistindo do registro das porcentagens de plântulas normais encontradas no quinto dia após a semeadura. O índice de velocidade de germinação (IVG) foi obtido em conjunto com o teste de germinação, computando-se diariamente, a partir do primeiro dia da semeadura até o último dia do teste de germinação, o número de plântulas normais, aplicandose depois a fórmula proposta por Maguire (1962). O envelhecimento acelerado foi avaliado com quatro repetições de 50 sementes de cada lote, empregando-se o "método gerbox" (citado por Marcos Filho (1999)), sob condições controladas de temperatura e umidade relativa do ar $\left(41^{\circ} \mathrm{C}\right.$ e $100 \%$ UR), durante 72 horas. Decorrido esse período, as sementes foram colocadas em rolos de papel Germitest e postas a germinar de maneira semelhante à descrita para o teste de germinação. A interpretação do teste foi realizada após cinco dias; a condutividade elétrica foi determinada por meio do sistema de massa, com quatro repetições de 50 sementes para cada lote. As sementes foram pesadas com precisão de duas casas decimais e, em seguida, colocadas em copos plásticos de $200 \mathrm{ml}$, com $75 \mathrm{ml}$ de água destilada e mantidas em germinador à temperatura constante de $25^{\circ} \mathrm{C}$. Após 24 horas de embebição, a condutividade elétrica da solução foi determinada em condutivímetro (VIEIRA, 1994), sendo depois os resultados expressos em $\mathrm{mScm}^{-1} \mathrm{~g}^{-1}$ com base no peso inicial das sementes (AOSA, 1983).

A análise estatística foi realizada de acordo com Banzatto e Kronka (2006), sendo realizado teste de Tukey para espaçamentos e regressão polinomial para doses de nitrogênio e aplicação, utilizando-se o Sistema de Análise Estatística para Microcomputadores - SANEST. Os dados porcentuais sofreram transformações em Arco Seno $(\% / 100)^{0,5}$. 


\section{RESULTADOS E DISCUSSÃO}

Os resultados referentes a todos o parâmetros avaliados estão expostos na Tabela 1. Observa-se que em relação ao teste de germinação não houve diferenças significativas em relação à população de plantas e também adubação nitrogenada, tanto na semeadura quanto em cobertura.

Tabela 1: Teste de germinação, primeira contagem, envelhecimento acelerado, índice de velocidade de germinação (IVG), condutividade elétrica e massa de 100 sementes de feijoeiro de inverno em função da aplicação de nitrogênio e população de plantas.

\begin{tabular}{|c|c|c|c|c|c|c|}
\hline Tratamentos & Germinação & $\begin{array}{l}\text { Primeira } \\
\text { contagem }\end{array}$ & $\begin{array}{c}\text { Envelhecimento } \\
\text { acelerado }\end{array}$ & IVG & $\begin{array}{c}\text { Condutividade } \\
\text { elétrica } \\
\left(\mathrm{mScm}^{-1} \mathrm{~g}^{-1}\right)\end{array}$ & $\begin{array}{c}\text { Massa } 100 \\
\text { sementes } \\
(\mathrm{g})\end{array}$ \\
\hline \multicolumn{7}{|c|}{ Espaçamentos (E) } \\
\hline $0,40 \mathrm{~m}$ & 99,5 & 98,7 & $93,29 \mathrm{~b}$ & 9,37 & 61 & 29,8 \\
\hline $0,50 \mathrm{~m}$ & 99,6 & 98,9 & $95,60 \mathrm{a}$ & 9,83 & 62 & 30,4 \\
\hline $0,60 \mathrm{~m}$ & 99,8 & 99,2 & $95,70 \mathrm{a}$ & 9,87 & 61 & 30,5 \\
\hline \multicolumn{7}{|c|}{$\mathrm{N}$ semeadura (NS) } \\
\hline $10 \mathrm{~kg} \mathrm{ha}^{-1}$ & 99,7 & 98,8 & 94,82 & 9,85 & 62 & 30,3 \\
\hline $20 \mathrm{~kg} \mathrm{ha}^{-1}$ & 99,6 & 99,1 & 95,02 & 9,89 & 61 & 30,2 \\
\hline \multicolumn{7}{|c|}{$\mathrm{N}$ cobertura $(\mathrm{NC})$} \\
\hline $0 \mathrm{~kg} \mathrm{ha}^{-1}$ & 99,7 & 99,3 & 95,25 & 9,89 & $61^{(1)}$ & 30,7 \\
\hline $25 \mathrm{~kg} \mathrm{ha}^{-1}$ & 99,4 & 98,2 & 96,32 & 9,81 & 62 & 31,0 \\
\hline $50 \mathrm{~kg} \mathrm{ha}^{-1}$ & 99,8 & 99,3 & 95,82 & 9,88 & 63 & 29,1 \\
\hline $75 \mathrm{~kg} \mathrm{ha}^{-1}$ & 99,7 & 99,0 & 95,22 & 9,88 & 64 & 30,2 \\
\hline $100 \mathrm{~kg} \mathrm{ha}^{-1}$ & 99,5 & 98,8 & 94,55 & 9,84 & 66 & 30,1 \\
\hline \multicolumn{7}{|c|}{ Interações } \\
\hline $\mathrm{E} \times \mathrm{NS}$ & ns & Ns & ns & ns & ns & ns \\
\hline $\mathrm{E} \times \mathrm{NC}$ & $\mathrm{ns}$ & Ns & ns & ns & ns & ns \\
\hline $\mathrm{NS} \times \mathrm{NC}$ & ns & Ns & ns & ns & ns & ns \\
\hline C.V. (\%) & 4,81 & 6,24 & 5,83 & 9,86 & 4,93 & - \\
\hline
\end{tabular}

$\mathrm{Y}=63,1729-0,0358 \mathrm{X}$

Médias seguidas de letra s distintas na coluna diferem a 5\% pelo teste de Tukey.

Carvalho et al. (1998) e Crusciol et al. (2003) obtiveram os mesmos resultados em relação a aplicação de $\mathrm{N}$ em semeadura e cobertura, sendo que todos os tratamentos apresentaram valores acima de 90\%, assim como Ambrosano et al. (1999), que ao estudarem os efeitos da adubação nitrogenada na qualidade de sementes do feijoeiro cultivar IACCarioca, independente do parcelamento ou da dose utilizada, observaram que não houve 
influência sobre a germinação. Por outro lado, Farinelli et al. (2006), observaram que o aumento das doses de $\mathrm{N}$ proporcionaram aumento linear na germinação de sementes de feijão, corroborando com resultados obtidos por Oliveira et al. (2006) que, independente das fontes utilizadas, obtiveram aumentos significativos na porcentagem de germinação em relação ao tratamento testemunha (43\%) para todas as doses de nitrogênio aplicadas. Os autores associaram os resultados ao fato do fornecimento de uma adubação balanceada durante o estádio vegetativo do feijão-vagem permitir o acúmulo de reservas sendo posteriormente translocadas paras as sementes para a formação do embrião e dos órgãos de reserva (TIMIRIAZEM, 1979; CARVALHO; NAKAGAWA, 2000).

Apesar da ausência de respostas, verifica-se que todos proporcionaram valores superiores a 99\%, ou seja, valores bem acima dos mínimos exigidos para a comercialização de sementes para a maioria dos estados brasileiros, que variam de 91 a 93\% (CARVALHO et al. 2001).

O teste de germinação é o método aplicado e recomendado para determinação da qualidade fisiológica da semente, embora se reconheçam as suas limitações, pois as condições a que as sementes são submetidas para germinar são próximas às adequadas (BRAGANTINI, 1996).

À semelhança da porcentagem de germinação, a $1^{\mathrm{a}}$ contagem também não foi influenciada por nenhum tratamento, no entanto, todos os tratamentos proporcionaram germinação superior a mínima admitida para o feijoeiro, que é de 80\% (Carvalho et al., 1998), concordando com os resultados obtidos por Carvalho et al. (1998), Ambrosano et al. (1999) e Crusciol et al. (2003).

Em relação ao teste de vigor expresso pelo teste de envelhecimento acelerado nota-se que a população de 300 mil plantas por hectare apresentou germinação inferior às outras populações. Os tratamentos com diferentes doses de $\mathrm{N}$ na semeadura e em cobertura não mostraram diferenças significativas. Esses resultados são discordantes de Farinelli et al. (2003) que observaram incrementos no vigor avaliado pelo envelhecimento acelerado promovido pela adubação nitrogenada de cobertura, porém, concordantes com Ambrosano et al. (1999) e Carvalho et al. (2001), que não notaram efeito positivo de doses e de épocas de aplicação de nitrogênio sobre a germinação e vigor (envelhecimento acelerado), para a cultivar IAC Carioca, no inverno.

O teste de condutividade elétrica demonstrou não haver influencia das populações de plantas e doses de $\mathrm{N}$ em semeadura, porém a condutividade aumentou, à medida que se aumentou a quantidade de $\mathrm{N}$ em cobertura. Crusciol et al. (2003) e Farinelli et al. (2006) 
também concluíram que as doses de $\mathrm{N}$ aplicadas em semeadura não provocam modificações significativas nas sementes, capazes de proporcionar uma lixiviação de eletrólitos diferenciada, em função das doses de N aplicadas na semeadura. Segundo Vieira et al. (1996) os resultados de vigor em sementes de feijão relativos ao teste de condutividade elétrica são influenciados de forma mais expressiva pelo fator genótipo/cultivar.

O índice de velocidade de germinação não apresentou resultados significativos para nenhum parâmetro analisado, o que contradiz, em relação à adubação nitrogenada na semeadura, os dados de Crusciol et al. (2003) e Oliveira et al. (2006). Os primeiros autores citados verificaram efeito significativo, onde a maior dose $(25 \mathrm{~kg} / \mathrm{ha})$ reduziu os valores dessa variável em relação à testemunha.

A massa de 100 sementes também não evidenciou diferenças significativas, mas apresentou uma tendência de populações menores propiciarem maior massa de grãos. Isso ocorreu provavelmente menor competição entre plantas, possibilitando uma maior translocação de assimilados e assim produzindo grãos com maior massa. De acordo com Jadoski et al. (2000), para a maioria das cultivares de feijão o aumento da população ocasiona reduções no rendimento de grãos por planta, número de vagens por planta e de grãos por vagem, sendo que a massa de mil sementes apresenta comportamento inverso. Quanto à adubação nitrogenada, também não foram observadas diferenças significativas, estando de acordo com Arf et al. (1999) que, trabalhando com doses e parcelamento da adubação nitrogenada em cobertura na cultura do feijão de inverno, em sistema plantio direto, verificaram que não houve efeito significativo para o parâmetro avaliado.

\section{CONCLUSÃO}

Menores populações de plantas proporcionam melhor qualidade fisiológica das sementes, pois apresenta sementes com maior vigor, evidenciado através do teste de envelhecimento acelerado. As diferentes doses de nitrogênio tanto na semeadura tanto em cobertura não interferem na qualidade fisiológica do feijoeiro. 


\section{REFERÊNCIAS}

AMBROSANO, E. J et al. Efeitos da adubação nitrogenada e com micronutrientes na qualidade de sementes do feijoeiro cultivar IAC - Carioca. Bragantia, Campinas, v.58, n.2, p.393-399, 1999.

AMBROSANO, E. J et al. Feijão In: RAIJ, B. Van. et al. Recomendações de adubação e calagem para o Estado de São Paulo, 2.ed. Campinas, Instituto Agronômico \& Fundação IAC, 1996. p.194-195. (Boletim Técnico, 100)

\section{AOSA - ASSOCIATION OF OFFICIAL SEED ANALYSIS. Seed vigour testing} handbook. East Lansing, 1983. 88p.

ARF, O et al. Efeito da rotação de culturas, adubação verde e nitrogenada sobre o rendimento do feijão. Pesq. Agrop. Brás., Brasília, v.34, n.11, p.2029-2036, 1999.

BANZATTO, D. A; KRONKA, S. N. Exp. Agr., Jaboticabal : Funep, 2006, 236 p.

BECKERT, O. P; MIGUEL, M. H; MARCOS FILHO, J. Absorção de água e potencial fisiológico em sementes de soja de diferentes tamanhos. Sci. Agr., v.57, n.4, p.671-675, 2000.

BRAGANTINI, C. Produção de sementes. In: ARAÚJO, R.S.; RAVA, C.A.; STONE, L.F.; ZIMMERMANN, M.J.O. (Ed.). Cultura do feijoeiro comum no Brasil. Piracicaba: Potafós, 1996. p.640- 652 .

BRASIL. Ministério da Agricultura e da Reforma Agrária. Regras para análise de sementes. Brasília: SNDA/DNDV/CLAV, 1992. 365p.

CARVALHO, E. G et al. Efeito de nitrogênio, molibdênio e inoculação das sementes em feijoeiro (Phaseolus vulgaris L.) na região de Selvíria, MS: II. Qualidade fisiológica e desempenho das sementes em campo. Científica, São Paulo, v.26, n.1/2, p.59-71, 1998.

CARVALHO, M. A. C et al. Produtividade e qualidade de sementes de feijoeiro (Phaseolus vulgaris L.) sob influência de parcelamento e fontes de nitrogênio. Rev. Brás. Ciênc. Solo, Campinas, v.25, n.3, p.617-624, 2001.

CARVAlHO, N. M; NAKAGAWA, J. Sementes: ciência, tecnologia e produção. Jaboticabal: FUNEP, 2000. 588p.

CRUSCIOL, C. A. C et al. Efeito do nitrogênio sobre a qualidade fisiológica, produtividade e caracterísiticas de sementes de feijão. Rev. Brás. Sem., v.25, n.1, p.108-115, 2003.

EMBRAPA - Empresa Brasileira de Pesquisa Agropecuária. Centro Nacional de Pesquisa de Solo. Sistema brasileiro de classificação de solos. Brasília, 1999. 412p.

FARINELLI, R et al. Produtividade e qualidade fisiológica de sementes de feijão em função de sistemas de manejo de solo e adubação nitrogenada. Rev. Brás. Sem.,, v.28, n.2, p.102109, 2006. 
JADOSKI, S. O et al. População de plantas e espaçamento entre linhas do feijoeiro irrigado. II: Rendimento de grão e componentes do rendimento. Ciênc. Rur. Santa Maria, v. 30, n.4, p.567-573. 2000.

MAGUIRE, L. D. Speed of germination-aid in selection and evolution for seedling emergence and vigor. Crop Science, Madison, v.2, n.2, p.176-177, 1962.

MARCOS FILHO, J. Teste de envelhecimento acelerado. In: KRZYZANOWSKI, F.C.; VIEIRA, R. D.; FRANÇA NETO, J.B. (Ed.) Vigor de sementes: conceitos e testes. Londrina: ABRATES, 1999. p.3.1-3.24.

OLIVEIRA, A. P. de et al. Produção e qualidade fisiológica de sementes de feijão-vagem em função de fontes e doses de nitrogênio. Rev. Brás. Sem., v.25, n.1, p.49-55, 2003.

TIMIRIAZEM, K.A. The use of plant analisis of the nutrition system for vegetable plant grow for seed production. Acta Hort., Wageningen, v.29, n.2, p.69-79, 1979.

VIEIRA , R. D et al. Efeito de genótipos de feijão e de soja sobre os resultados da condutividade elétrica de sementes. Rev. Brás. Sem., Brasília, v.18, n.2, p.220-224, 1996.

VIEIRA, R. D. Teste de condutividade elétrica. In: VIEIRA, R.D.; CARVALHO, N.M. (eds.). Teste de vigor em sementes. Jaboticabal: FUNEP, 1994. p.133-149.

VIEIRA, R. F; VIEIRA, C; RAMOS, J. A. O. Produção de sementes de feijão. Viçosa: EPAMIG/EMBRAPA, 1993. 131p. 
Nucleus, v.5, n.2, out. 2008 